\title{
Calcineurin-dependent regulation of Crz1p nuclear export requires Msn5p and a conserved calcineurin docking site
}

\author{
Leila M. Boustany and Martha S. Cyert ${ }^{1}$ \\ Department of Biological Sciences, Stanford University, Stanford, California 94305-5020, USA
}

Calcineurin, a conserved $\mathrm{Ca}^{2+} /$ calmodulin-regulated protein phosphatase, plays a crucial role in $\mathrm{Ca}^{2+}$ signaling in a wide variety of cell types. In Saccharomyces cerevisiae, calcineurin positively regulates transcription in response to stress by dephosphorylating the transcription factor Crz1p/Tcn1p. Dephosphorylation promotes Crz1p nuclear localization in part by increasing the efficiency of its nuclear import. In this work, we show that calcineurin-dependent dephosphorylation of Crz1p also down-regulates its nuclear export. Using a genetic approach, we identify Msn5p as the exportin for Crz1p. In addition, we define the Crz1p nuclear export signal (NES) and show that it interacts with Msn5p in a phosphorylation-dependent manner. This indicates that calcineurin regulates Crz1p nuclear export by dephosphorylating and inactivating its NES. Finally, we define a motif in Crz1p, PIISIQ, similar to the PxIxIT docking site for calcineurin on the mammalian transcription factor NFAT, that mediates the in vivo interaction between calcineurin and Crz1p and is required for calcineurin-dependent regulation of Crz1p nuclear export and activity. Therefore, in yeast as in mammals, a docking site is required to target calcineurin to its substrate such that it can dephosphorylate it efficiently.

[Key Words: S. cerevisiae; calcium signaling; calcineurin; Crz1p; Msn5p; nuclear transport]

Received December 4, 2001; revised version accepted January 18, 2002.

$\mathrm{Ca}^{2+}$-dependent signal transduction pathways elicit diverse physiological responses. One way that $\mathrm{Ca}^{2+}$ exerts an effect is through activation of the $\mathrm{Ca}^{2+}$-binding protein calmodulin, which, in turn, activates the serine/ threonine protein phosphatase calcineurin. In mammalian cells, calcineurin regulates the subcellular localization of the transcription factor NFAT (nuclear factor of activated $\mathrm{T}$-cells) that is required for T-cell activation in response to antigen. Dephosphorylation of NFAT by calcineurin promotes its nuclear localization and, as a result, gene transcription and T-cell proliferation (Flanagan et al. 1991; Jain et al. 1993; Shaw et al. 1995). Activation of NFAT is blocked, however, when calcineurin phosphatase activity is inhibited by the immunosuppressive drugs FK506/FK520 and cyclosporin A (Liu et al. 1991a; Clipstone and Crabtree 1992; O'Keefe et al. 1992). Calcineurin interacts with NFAT through a defined consensus binding site, PxIxIT; when this site is mutated, dephosphorylation and nuclear translocation of NFAT do not occur (Aramburu et al. 1998). Calcineurin similarly regulates NFAT family members in a variety of cell types to play a role in other processes including cardiac and skeletal muscle development and angiogenesis (Chin et al. 1998; de la Pompa et al. 1998; Molkentin et al. 1998; Ranger et al. 1998; Graef et al. 2001).

${ }^{1}$ Corresponding author.

E-MAIL mcyert@stanford.edu; FAX (650) 725-8309.

Article and publication are at http://www.genesdev.org/cgi/doi/10.1101/ gad.967602.
In the budding yeast Saccharomyces cerevisiae, calcineurin is activated by extracellular stresses. Calcineurin mutants deficient for either the catalytic subunits (CNA1/CNA2; Cyert et al. 1991; Liu et al. 1991b) or the regulatory subunit (CNB1; Kuno et al. 1991; Cyert and Thorner 1992) are viable under standard growth conditions but are sensitive to high concentrations of ions such as $\mathrm{Na}^{+}, \mathrm{Li}^{+}, \mathrm{Mn}^{+}$, and $\mathrm{OH}^{-}$(Nakamura et al. 1993; Mendoza et al. 1994; Farcasanu et al. 1995; Pozos et al. 1996). They also lose viability during sustained treatment with mating pheromone (Moser et al. 1996; Withee et al. 1997). Under these conditions calcineurin is required to activate a number of genes, including PMC1, $P M R 1$, and $P M R 2$, which encode ion pumps (Rudolph et al. 1989; Haro et al. 1991; Cunningham and Fink 1994, 1996; Mendoza et al. 1994), and FKS2, which encodes a major cell wall biosynthetic enzyme (Mazur et al. 1995). Calcineurin regulates transcription by activating Crzlp/ Tcnlp, which, in turn, binds a 24-bp promoter element termed the CDRE (calcineurin-dependent response element; Matheos et al. 1997; Stathopoulos and Cyert 1997) to activate transcription of its target genes.

Crzlp is regulated by calcineurin in a remarkably similar manner to NFAT; upon $\mathrm{Ca}^{2+}$ addition to the media, Crzlp rapidly translocates from the cytosol to the nucleus in a calcineurin-dependent fashion (Stathopoulos-Gerontides et al. 1999). Previous studies established that when Crzlp is dephosphorylated, its nuclear import rate increases because Crzlp binds to its importin 
Nmd5p more efficiently (Polizotto and Cyert 2001). Crzlp and NFAT are not homologous proteins but both do contain an SRR (serine-rich region) domain (Beals et al. 1997; Stathopoulos-Gerontides et al. 1999). In Crzlp mutants lacking the SRR, calcineurin-independent nuclear localization is observed, indicating that the SRR is important for regulation of Crzlp nuclear transport (Stathopoulos-Gerontides et al. 1999).

In this study we further characterize the calcineurindependent regulation of Crzlp nuclear transport. We establish that calcineurin negatively regulates Crzlp nuclear export and identify Msn5p as the required exportin. Furthermore, we define the Crzlp NES and show that its phosphorylation state is critical for function. Finally, we show that calcineurin interacts with Crzlp through a site, PIISIQ, that is similar to the calcineurinbinding site in NFAT; this motif is required for proper regulation of Crzlp nuclear transport by calcineurin and, thus, for wild-type Crzlp function.

\section{Results}

Crz1p nuclear export is regulated by calcineurin

$\mathrm{Ca}^{2+} /$ calcineurin-dependent dephosphorylation of Crzlp up-regulates nuclear import and causes rapid translocation of Crzlp from the cytosol to the nucleus of the cell (Polizotto and Cyert 2001). We wished to determine whether nuclear export of Crzlp was also regulated by calcineurin. To address this question, we used a strain deleted for the importin NMD5 such that we could observe Crzlp localization in the absence of calcineurinregulated nuclear import. Because Crzlp does not localize to the nucleus with $\mathrm{Ca}^{2+}$ addition in this strain (Polizotto and Cyert 2001), to facilitate Crzlp nuclear import we used an exogenous nuclear localization signal (NLS) from the SV40 large $\mathrm{T}$ antigen (Kalderon et al. 1984a,b). The SV40 NLS targeted GFP to the nucleus; this targeting was unaffected by $\mathrm{Ca}^{2+}$ or FK506 addition to the media (Fig. 1), and thus is not regulated by calcineurin. The GFP-SV40NLS-Crz1p fusion localized to the cytosol of untreated cells, showing that Crzlp contains an NES and suggesting that under these conditions the rate of Crzlp nuclear export is greater than the rate of import directed by the SV40 NLS. However, when $\mathrm{Ca}^{2+}$ was added, GFP-SV40NLS-Crzlp localized to the nucleus of $n m d 5 \Delta$ cells (Fig. 1). This change did not occur when calcineurin was inhibited by FK506. Because the SV40 NLS provides constant nuclear import, we concluded that the $\mathrm{Ca}^{2+}$-induced nuclear localization of GFP-SV40NLS-Crzlp was owing to decreased export. Thus, dephosphorylation of Crzlp by calcineurin leads to decreased nuclear export.

\section{A genetic screen identifies MSN5 as the Crz1p exportin}

To establish the mechanism of Crzlp nuclear export, we devised a genetic screen to identify the Crzlp exportin. Previous studies revealed that expression of the

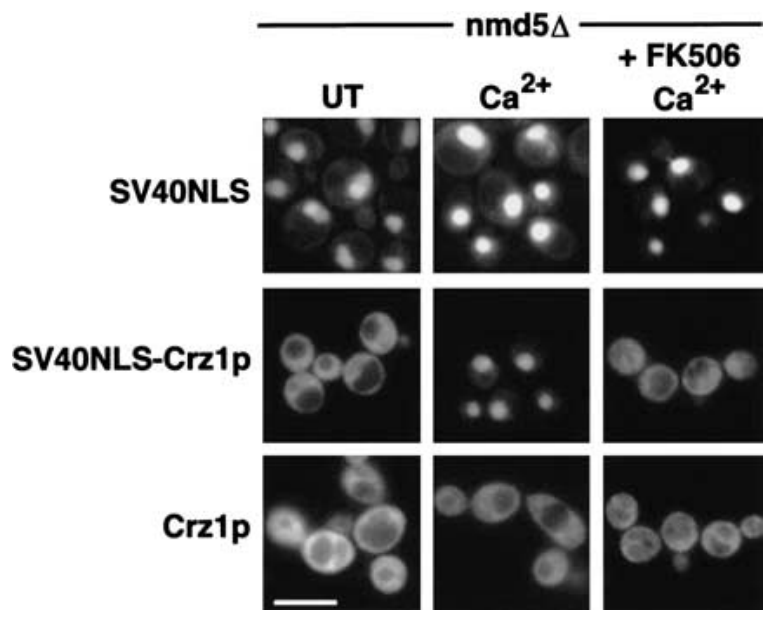

Figure 1. Crzlp nuclear export is regulated by calcineurin. $n m d 5 \Delta$ (HFY133) cells expressing 3xGFP-SV40NLS (LMB134), 3xGFP-SV40NLS-Crz1p (LMB148), or 3xGFP-Crz1p (LMB127) were grown to $\log$ phase at $21^{\circ} \mathrm{C}$. Cells were treated with 200 $\mathrm{mM} \mathrm{CaCl}_{2}$ or pretreated with FK506 $(2 \mu \mathrm{g} / \mathrm{mL})$ for $30 \mathrm{~min}$ before $\mathrm{CaCl}_{2}$ addition and visualized using fluorescence microscopy. Bar, $20 \mu \mathrm{m}$.

CDRE::1acZ reporter element is dependent on both calcineurin and Crz1p (Stathopoulos and Cyert 1997). We reasoned that a mutation in the exportin for Crzlp might result in constitutive nuclear localization of Crzlp and consequent activation of the CDRE::1acZ reporter in a calcineurin mutant background $(c n b 1 \Delta)$. We identified 40 recessive mutants that expressed CDRE::1acZ in the absence of calcineurin activity, and a single complementation group containing 5 strains was chosen for characterization (see Materials and Methods). These strains were complemented by plasmids containing MSN5. Fur-

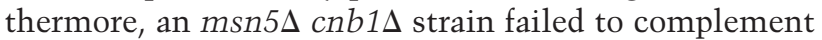
the mutants, confirming that each contained a mutation in MSN5. The msn5s cnb1s strain also had the same phenotype as the mutant isolated from our screen (msn5$11 \mathrm{cnb} 1 \Delta)$. In a quantitative $\beta$-galactosidase assay, both strains showed a small but reproducible increase in basal CDRE::lacZ activity over the cnb1s strain (Fig. 2A). Therefore, we used the null allele of MSN5 for all further experiments.

\section{Mutations in MSN5 affect Crz1p cellular localization}

Because Msn5p had been previously characterized as a nuclear transport factor (Kaffman et al. 1998; Blondel et al. 1999; DeVit and Johnston 1999|, we tested whether mutations in MSN5 affected Crzlp localization. GFPCrzlp localizes to the cytosol of untreated cells, but translocates to the nucleus after $\mathrm{Ca}^{2+}$ addition to the media (Fig. 2B; Stathopoulos-Gerontides et al. 1999). This change in localization is completely dependent on calcineurin as GFP-Crzlp remains cytosolic in a $c n b 1 \Delta$ strain. In contrast, GFP-Crzlp was partially localized to the nucleus of msn5s cnb1s cells (Fig. 2B). $\mathrm{Ca}^{2+}$ addition had no further effect on GFP-Crzlp localization in this strain, as would be expected in the absence of calcineu- 
Figure 2. msn5 mutants activate Crzlpdependent transcription in a cnb1s background and alter Crzlp subcellular localization. (A) Strains harboring an integrated CDRE::1acZ reporter were grown to $\log$ phase at $30^{\circ} \mathrm{C}$ and harvested. $\beta$-Galactosidase activity was measured for cnb1s (DD12), msn5-11cnb1s (ASY11), and msn5s cnb1s (LBY196) strains. For each strain two cell extracts were prepared and assayed in triplicate. The standard deviation is the error between the samples. $(B)$ WT (ASY472), cnb1s (ASY475), and msn5s cnb1s (LBY172) cells expressing GFP-Crzlp (AMS463) were grown to log phase at $21^{\circ} \mathrm{C}$. Cells were treated with 200 $\mathrm{mM} \mathrm{CaCl}$, and GFP-Crzlp was visualized using fluorescence microscopy. Bar, $20 \mu \mathrm{m} .(C)$ Msn5p does not affect Crzlp phosphorylation state. Whole cell extracts from wild-type (YPH499), cnb1s (DD12), and msn5s (ASY788) strains containing HA-Crzlp (AMS446) were treated with or without $2 \mu \mathrm{g} / \mathrm{mL}$ FK520 and analyzed by Western blot using anti-HA antibody.

A

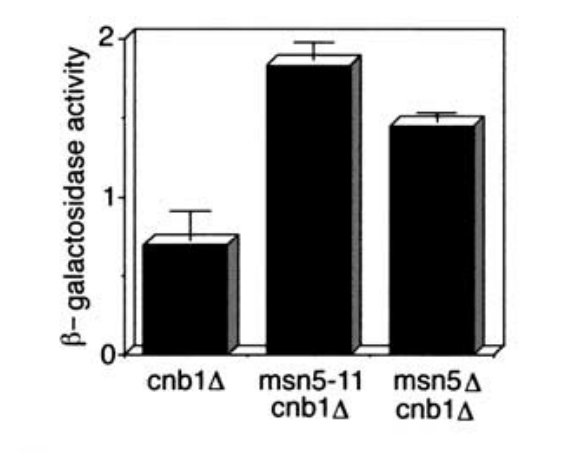

C

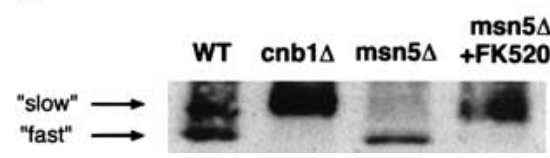

B

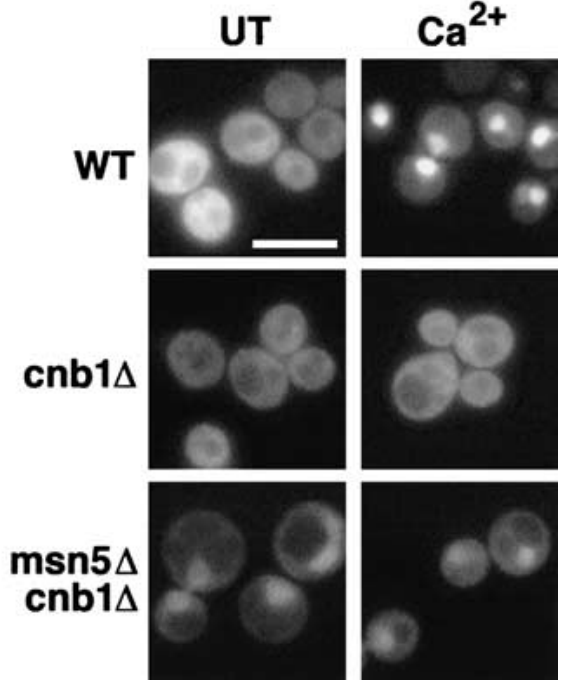

rin activity. The nuclear accumulation of Crzlp observed in untreated msn5s cnb1s cells is consistent with a defect in Crzlp nuclear export.

Crzlp subcellular localization is regulated by its phosphorylation state (Stathopoulos-Gerontides et al. 1999; Polizotto and Cyert 2001); therefore, we examined whether Msn5p affects Crzlp phosphorylation. Crzlp shows a faster electrophoretic mobility in wild-type strains than it does in $c n b 1 \Delta$ strains (Fig. 2C; Stathopoulos-Gerontides et al. 1999). This difference is due to phosphorylation because treatment of purified Crzlp with calcineurin in vitro eliminates the mobility shift (Stathopoulos-Gerontides et al. 1999). We determined that the electrophoretic mobility of HA-Crzlp also showed a calcineurin-dependent shift in msn5s strains. When $m s n 5 \Delta$ cells were incubated with the calcineurin inhibitor FK520, Crzlp showed reduced mobility (Fig. 2C). Thus, in the absence of Msn5p and calcineurin activity, Crzlp is phosphorylated, yet it accumulates in the nucleus.

\section{Msn5p is required for Crz1p nuclear export}

We next sought to determine whether Msn5p is required for Crzlp export from the nucleus. To address this question, wild-type or msn5s cells expressing GFP-Crzlp were first treated with the protein synthesis inhibitor cycloheximide to ensure that we followed the same pool of GFP-Crzlp throughout the experiment. $\mathrm{Ca}^{2+}$ was added to promote nuclear localization of GFP-Crzlp, and cells were subsequently incubated with FK506 for 30 min to inhibit calcineurin activity. In wild-type cells, FK506 treatment caused GFP-Crzlp to return to the cytosol (Fig. 3), indicating that continual dephosphorylation of Crzlp by calcineurin is required to maintain its nuclear localization. However, in msn5s cells, GFPCrzlp remained nuclear even after treatment with FK506 (Fig. 3), suggesting that Msn5p is required for Crzlp to exit the nucleus. Notably, the addition of $\mathrm{Ca}^{2+}$ to $\operatorname{msn} 5 \Delta$ cells led to increased nuclear localization of GFP-Crzlp (Fig. 3). Because export is blocked in these cells, this change in localization is likely caused by increased nuclear import of Crzlp, and provides further evidence for the role of $\mathrm{Ca}^{2+} /$ calcineurin in regulating this process (Polizotto and Cyert 2001).

\section{Identification of the Crz1p NES}

To further explore the mechanism of Crzlp nuclear export, we identified the Crzlp NES. We tested the ability of different portions of Crzlp to drive export of the constitutively nuclear GFP-SV40NLS fusion. Using this ap-

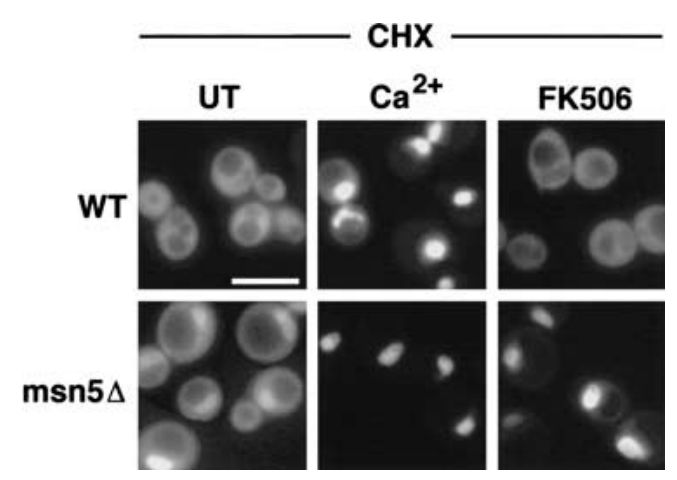

Figure 3. Msn5p is required for Crzlp nuclear export. WT (ASY472) and msn5s (ASY788) cells expressing GFP-Crzlp (AMS463) were grown to $\log$ phase at $21^{\circ} \mathrm{C}$. Cells were treated with cycloheximide $(10 \mu \mathrm{g} / \mathrm{mL})$ for $20 \mathrm{~min}$. $\mathrm{CaCl}_{2}(200 \mathrm{mM})$ was added for $10 \mathrm{~min}$ followed by FK506 $(5 \mu \mathrm{g} / \mathrm{mL})$. Images were captured 30 min after FK506 treatment. Bar, $20 \mu \mathrm{m}$. 
proach, we defined two distinct domains. One domain was required for calcineurin-dependent regulation of Crzlp nuclear export and is described in detail below. The other domain, amino acids 186-279, was sufficient to cause cytosolic localization of GFP-SV40NLS in the presence and absence of $\mathrm{Ca}^{2+}$ (Fig. 4A) as well as in a $c n b 1 \Delta$ strain (data not shown). In an msn5s background, however, GFP-SV40NLS-Crzlp ${ }_{186-279}$ is nuclear (data not shown). Thus, amino acids 186-279 of Crzlp contain an Msn5p-dependent NES. Residues 186-279 define the smallest region sufficient for nuclear export as GFPSV40NLS-Crzlp ${ }_{186-250}$ and GFP-SV40NLS-Crzlp $p_{201-279}$ both failed to be exported (Fig. 4A,B). It is likely that this is the only NES in Crzlp because constructs encompassing the $\mathrm{N}$ terminus (amino acids $1-186$ ) or the $\mathrm{C}$ terminus (amino acids 433-679) of the protein failed to be exported (Fig. 4B). Interestingly, the NES includes the SRR domain, which contains many putative Crzlp phosphorylation sites. The SRR is not sufficient for export, but it is necessary; when this region was deleted $(\Delta 186-$ 233), export activity was lost (Fig. 4B). In addition, when all serines and two threonines in the SRR domain were mutated to alanine (mSRR), export activity was again disrupted, suggesting that phosphorylation of the NES is required for its function (Fig. 4A, B). Mutating different subsets of serines in the SRR resulted in less severe export defects (data not shown); thus, elimination of multiple sites is required to disrupt the NES.

\section{Msn5p interacts with the Crz1p NES}

We examined the interaction between the Crzlp NES and Msn5p using a directed yeast two-hybrid approach. Amino acids 186-279 of Crzlp fused to the Gal4p activation domain $\left(\mathrm{AD}-\mathrm{CRZ1} 1_{186-279}\right)$ interacted with Msn5p fused to the Gal4p DNA-binding domain (BD-MSN5; Fig. 4C; DeVit and Johnston 1999). Yeast containing a GAL4 UAS-driven HIS3 reporter showed robust growth on media lacking histidine when both fusions were expressed, whereas yeast expressing either construct alone showed little or no growth. Therefore, Msn5p physically interacts with the Crzlp NES in vivo. However, Msn5p failed to interact with $\mathrm{AD}-\mathrm{mSRR}_{186-279}$ containing serine/threonine to alanine changes (Fig. 4C), suggesting that phosphorylation is required for binding between Crzlp and Msn5p and, thus, for nuclear export.
A
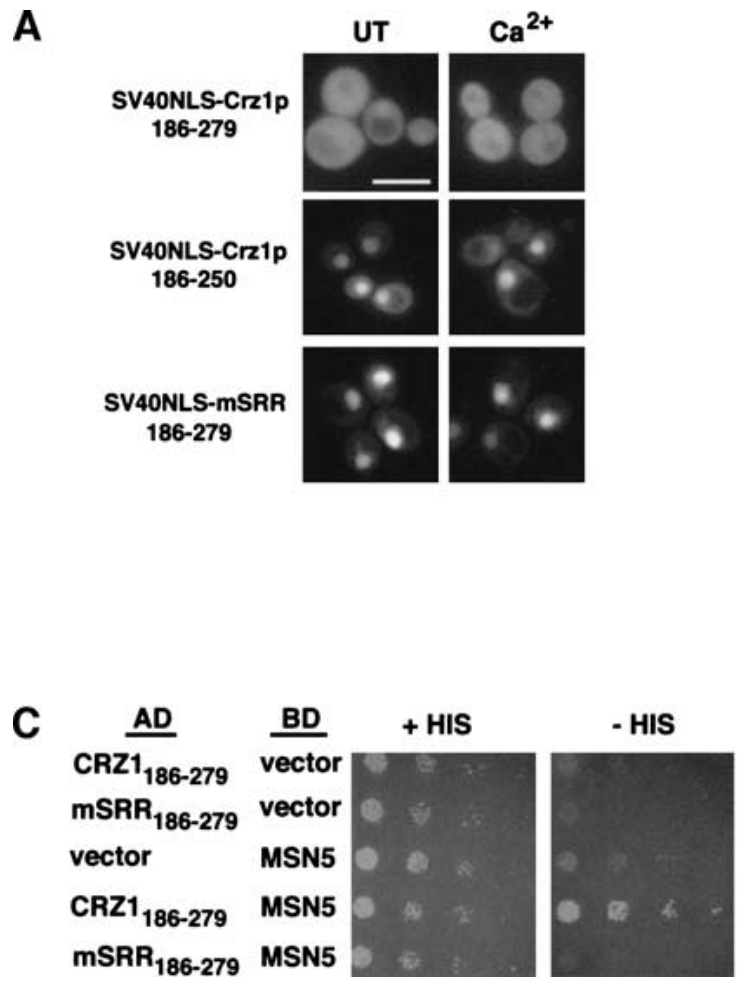

B

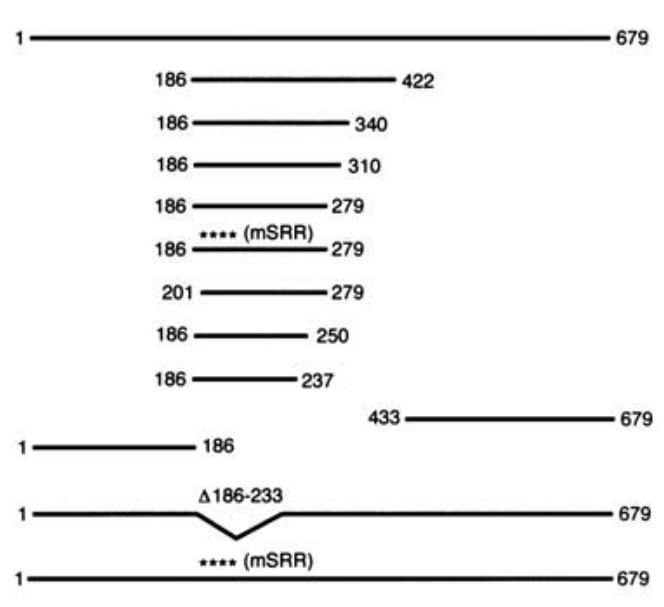

D

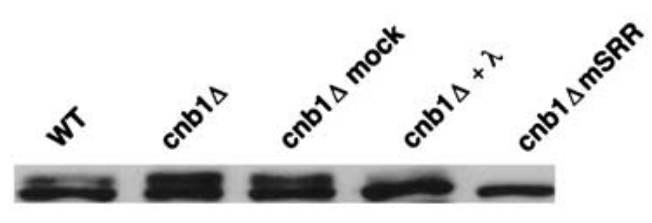

Figure 4. Identification of the Crzlp NES. (A) WT (ASY472) cells expressing 3xGFP-SV40NLS-Crzlp 186-279 (LMB162), 3xGFP-

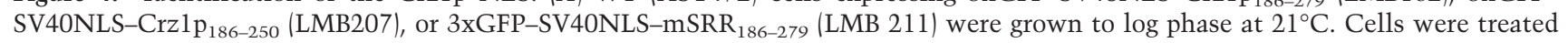
with $200 \mathrm{mM} \mathrm{CaCl}_{2}$ and visualized using fluorescence microscopy. Bar, $20 \mu \mathrm{m}$. (B) Summary of export data for 3xGFP-SV40NLSCrzlp constructs. $(+)$ Cytosolic localization (export); (-) nuclear localization (no export). $(C)$ The Crzlp NES interacts with Msn5p in vivo. A two-hybrid strain containing a HIS3 reporter (PJ69-4A) expressing AD-CRZ1 186-279 (LMB193), AD-mSRR $186-279$ (LMB218), or GAL4BD-MSN5 (BM3694) alone or in combination was spotted onto media with or without histidine and grown at $21^{\circ} \mathrm{C}$ for $5 \mathrm{~d}$. Cells were spotted using fivefold serial dilutions beginning at an $\mathrm{OD}_{600}$ of 0.05 . $(D)$ The Crzlp NES is similarly phosphorylated in WT and cnb1s cells. Whole cell extracts from WT (ASY472) or cnb1s (ASY475) strains containing LMB162 or LMB211 were analyzed by Western blot using anti-GFP antibody. Where indicated, extracts were treated with or without (mock) 200 units of $\lambda$ phosphatase and incubated at $30^{\circ}$ for $30 \mathrm{~min}$. 
Our data indicate that phosphorylation within the SRR domain is required for NES activity; therefore, we investigated the phosphorylation state of the NES under different conditions. We examined GFP-SV40NLSCrzlp $p_{186-279}$ protein isolated from wild-type and $c n b 1 \Delta$ backgrounds. Unlike full-length Crzlp (Fig. 2C), the NES showed similar electrophoretic mobility in wild-type and cnb1s cells (Fig. 4D). An upper band was evident in both samples that was missing in the GFP-SV40NLSmSRR $_{186-279}$ sample, where all putative phosphorylation sites had been mutated. When dephosphorylated in vitro, the protein collapsed to a single band, showing that the upper band was, indeed, a result of phosphorylation (Fig. 4D). Therefore, in this context, the NES directs export in wild-type and $c n b 1 \Delta$ cells and shows similar phosphorylation in both strains. These observations are consistent with our hypothesis that phosphorylation of the Crzlp NES is required for interaction with Msn5p.

\section{Identification of the Crz1p export regulatory region}

Full-length Crzlp shows calcineurin-dependent regulation of nuclear export, but the NES defined above, amino acids $186-279$, is exported independently of calcineurin activity. To explore this difference, we used additional GFP-SV40NLS-Crzlp fusions to examine the mechanism by which calcineurin regulates Crzlp nuclear export. GFP-SV40NLS-Crzlp $186-340$ was the smallest fusion that behaved like full-length Crzlp. It localized to the nucleus of wild-type cells upon $\mathrm{Ca}^{2+}$ addition but remained cystosolic in cnb1s cells (Fig. 5A). A smaller fusion, GFP-SV40NLS-CRZ1 $1_{186-310}$, was cytosolic in both wild-type and $c n b 1 \Delta$ backgrounds with or without $\mathrm{Ca}^{2+}$ addition (Fig. 5A). Therefore, amino acids 311-340 are required for calcineurin-dependent regulation of Crzlp export.

To further investigate the effect of calcineurin activity on Crzlp nuclear export, we examined the localization of GFP-SV40NLS-Crzlp constructs in strains overexpressing a constitutively active, truncated form of calcineurin, CNA2 trunc (Withee et al. 1997). GFP-SV40NLS-Crzlp $186-340$ was nuclear in this background even in the absence of $\mathrm{Ca}^{2+}$ (Fig. 5B). This construct lacks a calcineurin-dependent NLS, hence, its nuclear localization must result from down-regulated export. In contrast, expression of activated calcineurin
A
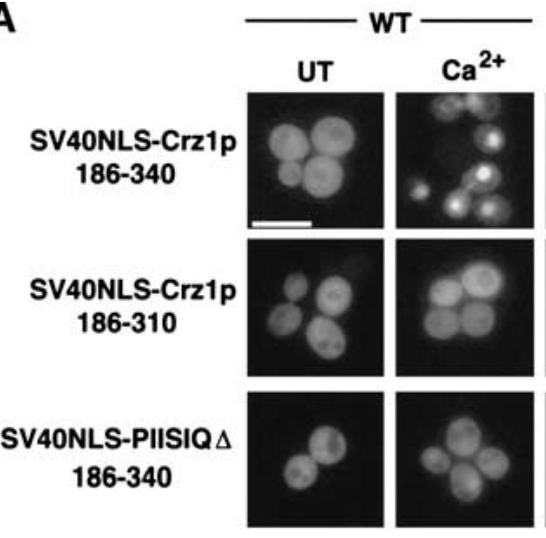

cnb1 $\Delta$
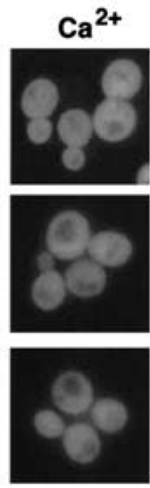

C
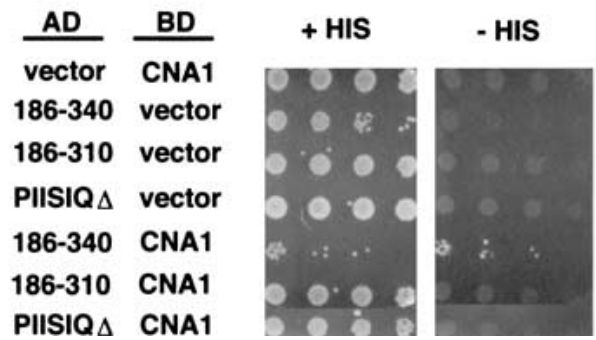

B

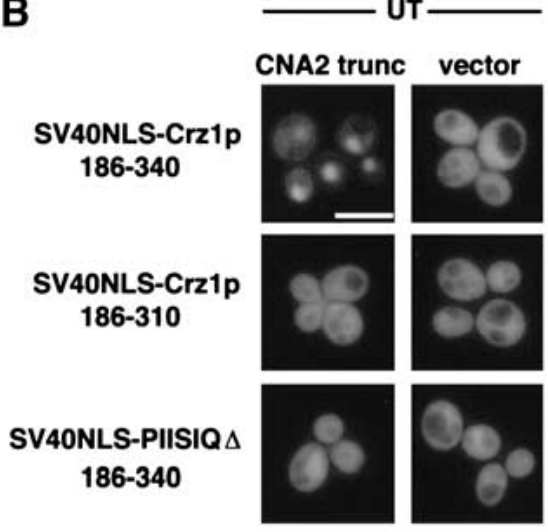

D

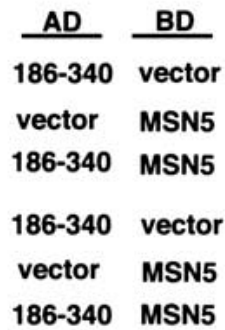

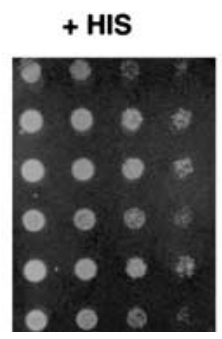

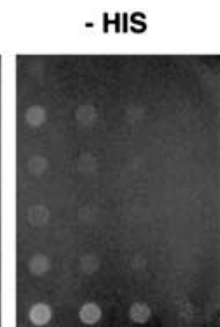

Figure 5. Identification of the export regulatory region. (A) WT (ASY472) or cnb1 (ASY475) cells expressing 3xGFP-SV40NLS-

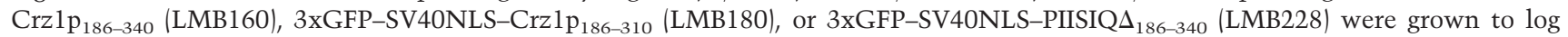
phase at $21^{\circ} \mathrm{C}$. Cells were treated with $200 \mathrm{mM} \mathrm{CaCl}_{2}$ and visualized using fluorescence microscopy. Bar, $20 \mu \mathrm{m}$. (B) Overexpression

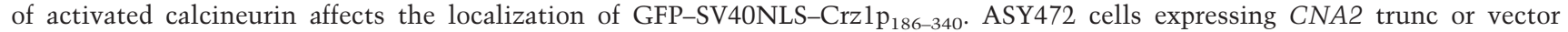
(pVT100-L) and LMB160, LMB180, or LMB228 were grown to log phase at $21^{\circ} \mathrm{C}$ and visualized using fluorescence microscopy. Bar, 20 $\mu \mathrm{m} .(C)$ Constructs containing the Crzlp export regulatory region interact with calcineurin in vivo. A two-hybrid strain (PJ69-4A) containing a HIS3 reporter and expressing GAL4AD-Crz1p fusions LMB189, LMB226, or LMB224 and GAL4BD-CNA1 (BJP2014) alone or in combination were spotted on plates with or without histidine plus $100 \mathrm{mM} \mathrm{CaCl}_{2}$ and grown at $30^{\circ} \mathrm{C}$ for $2-3 \mathrm{~d}$. Cells were spotted using fivefold serial dilutions beginning at an $\mathrm{OD}_{600}$ of 1.0. $(D)$ The Crzlp/Msn5p interaction is dependent on Crzlp phosphorylation state. WT and cnb1s two-hybrid strains (PJ69-4A and ASY3) containing a HIS3 reporter and expressing LMB189 and GAL4BD-MSN5 (BM3694) alone or in combination were spotted on media with or without histidine plus $100 \mathrm{mM} \mathrm{CaCl}_{2}$ and grown at $21^{\circ} \mathrm{C}$ for $5 \mathrm{~d}$. Cells were spotted using fivefold serial dilutions beginning at an $\mathrm{OD}_{600}$ of 1.0 . 
had no effect on the cytosolic localization of GFPSV40NLS-Crzlp $186-310$ (Fig. 5B).

We hypothesized that residues $311-340$ of Crzlp are required for its association with calcineurin. Using a directed yeast two-hybrid approach, we looked for an interaction between calcineurin (Cnalp) and Crzlp. AD$\mathrm{CRZ1}_{186-340}$, the region that shows regulated nuclear localization, interacted with BD-CNA1 (Jiang and Cyert 1999|, but AD-CRZ1 ${ }_{186-310}$ did not (Fig. 5C). In addition, an examination of phosphorylation state revealed that, like amino acids $186-279$, residues $186-310$ were phosphorylated in both wild-type and cnb1s backgrounds (data not shown). These findings support the idea that residues 311-340 of Crzlp are required for its interaction with and efficient dephosphorylation by calcineurin.

A consensus binding site for calcineurin in NFAT family members has been defined, PxIxIT (Aramburu et al. 1998) We identified a similar site, PIISIQ (PxIxIQ), within amino acids 311-340 of Crzlp and examined its role in calcineurin-dependent regulation of Crzlp. First, GFP-SV40NLS-Crzlp ${ }_{186-340}$ lacking the PIISIQ motif (GFP-SV40NLS-PIISIQ $\left.\Delta_{186-340}\right)$ no longer localized to the nucleus with $\mathrm{Ca}^{2+}$ addition (Fig. 5A). Next, we examined the effect of activated calcineurin on GFPSV40NLS-PIISIQ $\Delta_{186-340}$ localization and found that it remained cytosolic (Fig. 5B). Finally, we tested whether these residues were necessary for Crzlp/calcineurin interaction and found by two-hybrid analysis that AD-PIISIQ $\Delta_{186-340}$ failed to interact with BD-CNA1 (Fig. 5C). These data suggest that the PIISIQ motif is a docking site for calcineurin on Crzlp and is required for calcineurindependent regulation of Crzlp nuclear export. We hypothesized that Crzlp fragments containing the PIISIQ motif are dephosphorylated by calcineurin, and thus, they show calcineurin-regulated nuclear export. In contrast, smaller pieces of Crzlp that lack the PIISIQ motif, such as 186-279 and 186-310, are not efficiently dephosphorylated by calcineurin, and therefore show unregulated nuclear export. If this model is correct, then Crzlp ${ }_{186-340}$ but not Crzlp 186-279 should show a calcineurin-sensitive interaction with the exportin Msn5p. We confirmed this prediction using two-hybrid analysis. Amino acids 186-340 of Crzlp interacted more strongly with Msn5p in a cnb1s background than in a wild-type strain (Fig. 5D). However, we found that residues 186279 (NES) interacted similarly with Msn5p in both wildtype and $c n b 1 \Delta$ strains (data not shown).

\section{Deleting the PIISIQ motif affects Crz1p function}

We established that amino acids $311-340$ are required for calcineurin-dependent regulation of protein fusions containing small regions of Crzlp. To determine the function of this region in full-length Crzlp, we examined the localization of GFP-Crzlp constructs with in-frame deletions of either residues $311-340$ or 331-336 (PIISIQ). These constructs lack the SV40NLS, relying instead on the endogenous Crz1p NLS for Nmd5p-mediated nuclear import. As previously shown, full-length GFP-Crzlp localized to the nucleus within $10 \mathrm{~min}$ of $\mathrm{Ca}^{2+}$ addition to the media (Fig. 6A). GFP-Crzlp ${ }_{311-340 \Delta}$ and GFPCrzlp pisiQs, however, remained cytosolic under these conditions (Fig. 6A). At longer times, partial nuclear localization of GFP-Crzlp $p_{311-340 \Delta}$ and GFP-Crzlp PIISIQ $\Delta$ was observed (data not shown). Therefore, the PIISIQ motif is required for efficient nuclear localization of Crzlp in response to $\mathrm{Ca}^{2+}$. Next, we tested the ability of these constructs to complement the $\mathrm{Li}^{+}$sensitivity of crz1s strains. When plated on $350 \mathrm{mM} \mathrm{LiCl}_{2}, \mathrm{GFP}-$ Crzlp fully complemented the crz1s, whereas GFPCrzlp p11-340s $_{311}$ and GFP-Crzlp $p_{\text {PIISIQ }}$ did not (Fig. 6B). Finally, we analyzed the transcriptional activity of the de-
A

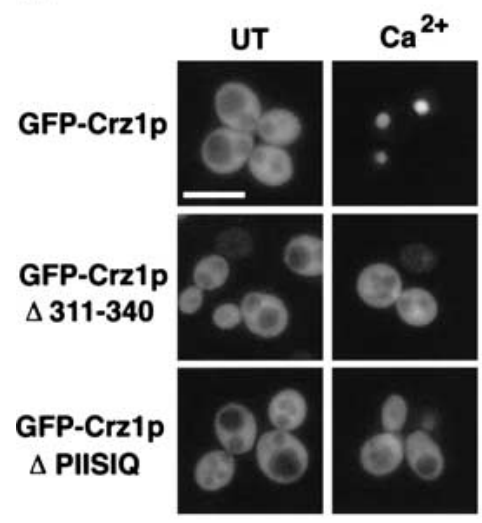

B

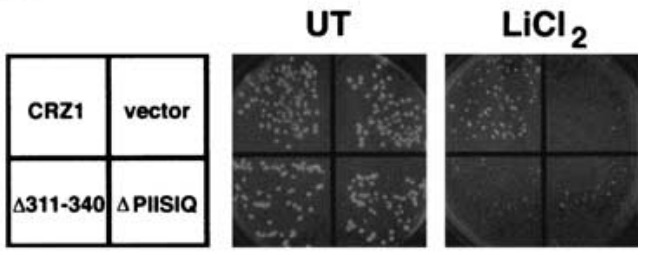

C

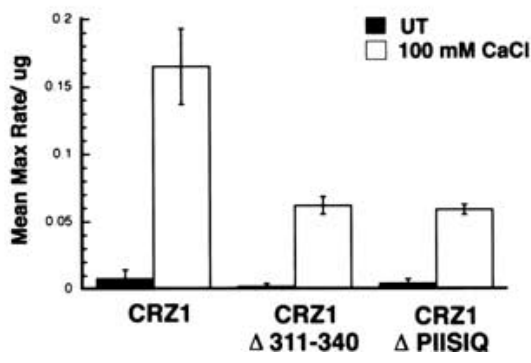

Figure 6. Deletion of the PIISIQ motif affects Crzlp localization. (A) WT (ASY472) cells expressing 3xGFP-Crzlp (LMB127), 3xGFP-Crzlp ${ }_{\Delta 311-340}$ (LMB230),

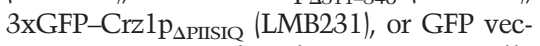
tor were grown to $\log$ phase at $21^{\circ} \mathrm{C}$. Cells were treated with $200 \mathrm{mM} \mathrm{CaCl}_{2}$ for 10 $\mathrm{min}$ and visualized with fluorescence microscopy. Bar, $20 \mu \mathrm{m}$. (B) The PIISIQ motif is required for complementation of a crz1s strain. ASY472 cells expressing LMB127, LMB230, LMB231, or GFP vector were plated on selective media with or without $350 \mathrm{mM} \mathrm{LiCl}_{2}$ and grown at $30^{\circ} \mathrm{C}$ for $3 \mathrm{~d} .(\mathrm{C})$ Deletion of the PIISIQ motif affects Crzlp activity. $\beta$-Galactosidase activity was measured in crz1 $1 \Delta$ cells harboring an integrated CDRE::1acZ reporter (ASY834). Strains expressed LMB127, LMB230, or LMB231 and were treated with (open bars) or without (black bars) $100 \mathrm{mM} \mathrm{CaCl}{ }_{2}$. The numbers are the result of two replicates analyzed in triplicate, and the standard deviation is the error between samples. 
letion constructs. Full-length GFP-Crzlp activated transcription of the CDRE::1acZ reporter in response to $\mathrm{Ca}^{2+}$ (Fig. 6C), whereas crz1s strains expressing vector alone showed no $\mathrm{Ca}^{2+}$ induction (data not shown). The ability of the deletion constructs to drive transcription of CDRE::1acZ was reduced (Fig. 6C), although all three fusion constructs were expressed at equivalent levels (data not shown). Together, these data indicate that the PIISIQ motif is required in vivo for maximal activation of Crzlp.

\section{Discussion}

\section{Calcineurin regulates nuclear export of Crz1p}

In vivo, activation of yeast calcineurin causes rapid translocation of the Crzlp transcription factor from the cytosol to the nucleus, where it turns on transcription of specific target genes. Studies from this laboratory have characterized the nuclear transport of Crzlp to elucidate the mechanisms by which this change in localization occurs. In this report we examined export of Crzlp from the nucleus and showed that calcineurin down-regulates Crzlp export. To understand how calcineurin regulates this process, we identified the key elements of Crzlp nuclear export: its exportin and its NES.

\section{Msn5p is the exportin for Crz1p}

We have determined that Msn5p is the exportin for Crzlp. Crzlp is partially nuclear in msn5s cells even when calcineurin is inactive, and this allows calcineurin-independent expression of the CDRE::1acZ reporter. Furthermore, once Crzlp is in the nucleus, Msn5p is required for its return to the cytosol. Although we were unable to show direct binding between Crzlp and Msn5p in vitro, perhaps because it is a weak interaction or other stabilizing proteins are necessary, we do show that Msn5p interacts with the Crzlp NES by two-hybrid analysis. Msn5p has been identified as the exportin for several other proteins including Pho4p, Miglp, Farlp, and Ste5p (Kaffman et al. 1998; Blondel et al. 1999; DeVit and Johnston 1999; Mahanty et al. 1999; Kunzler et al. 2001) and appears to also function in some cases as an importin (Yoshida and Blobel 2001), providing the first example of a karyopherin that functions bidirectionally.

Interestingly, MSN5 was isolated both in a screen for mutants that activate a calcineurin/Crzlp-dependent reporter (this work) and in a screen for mutants that fail to do so (Matheos et al. 1997). In msn5 mutants, we find that Crzlp accumulates in the nucleus and allows calcineurin-independent expression of CDRE::IacZ. However, msn5 cells fail to induce expression of the $\mathrm{Ca}^{2+}$ activated calcineurin/Crzlp-dependent PMC1::1acZ reporter gene (Matheos et al. 1997). This apparent contradiction may result from differences between the two reporters: CDRE::1acZ consists of four tandem repeats of a 24-bp sequence that binds Crzlp (Stathopoulos and Cyert 1997), whereas PMC1::1acZ contains 585 bp of DNA upstream of the PMC1 start site /Cunningham and Fink 1996). Thus, although the CDRE reporter specifi- cally reflects Crz1p activity, the PMC1 promoter could contain binding sites for numerous proteins. Msn5p is pleiotropic and affects localization of several proteins (Kaffman et al. 1998; Alepuz et al. 1999; Blondel et al. 1999; DeVit and Johnston 1999; Mahanty et al. 1999). Therefore, in msn5 cells, a protein that represses transcription of PMC1::1acZ may also accumulate in the nucleus and prevent its expression despite Crzlp nuclear localization.

\section{The Crz1p NES}

The Crzlp NES does not share the same characteristics as the classical NES. As defined in the protein kinase A inhibitor (PKI) and HIV-1 Rev, the classical NES is a short leucine-rich sequence in which the key residues are all hydrophobic (Fischer et al. 1995; Wen et al. 1995), and is recognized by the exportin Crm1p (Fornerod et al. 1997; Ossareh-Nazari et al. 1997; Stade et al. 1997). In Crzlp, we have instead defined a much larger 93-aminoacid region that is sufficient to drive nuclear export. This length is consistent with the sequences identified in other Msn5p cargoes (Blondel et al. 1999; DeVit and Johnston 1999). It is not yet understood why such a large NES is required for Msn5p-mediated export. Perhaps there are multiple NES sequences within the large region that work cooperatively. Alternatively, NES secondary structure rather than a specific amino acid sequence may be important for recognition by Msn5p. Interestingly, the Crzlp NES (amino acids 186-279) does contain one classical leucine-rich sequence, LDDLLSL (amino acids 257-263) that is necessary for its activity. The Crzlp NES also contains the SRR, a domain that is conserved between NFAT and Crzlp (see below). Although in NFAT the SRR was shown to be involved in regulating nuclear import (Beals et al. 1997; Okamura et al. 2000), our data show that it plays a key role in nuclear export, which is a novel function for the Crzlp SRR.

\section{Mechanism of calcineurin-regulated Crz1p nuclear export}

Calcineurin must interact with a conserved docking site in Crzlp to regulate its nuclear export. Crzlp fragments lacking the PIISIQ motif are constitutively exported and are unaffected by the overexpression of activated calcineurin. We propose that this motif is required for Crzlp to interact with and be efficiently dephosphorylated by calcineurin. In support of this model, we show using two-hybrid analysis that Crzlp ${ }_{186-340}$ interacts with calcineurin, but that it fails to do so when the PIISIQ motif is deleted. Also, fusion proteins containing residues 186310 or $186-279$, both missing the PIISIQ motif, are similarly phosphorylated in extracts of wild-type and calcineurin mutant cells, indicating that they are not dephosphorylated in vivo.

Several results suggest that the Crzlp NES must be phosphorylated to function. First, in the two-hybrid assay, Msn5p preferentially interacts with phosphorylated Crzlp $p_{186-340}$. Second, mutating potential phosphoryla- 
tion sites within the Crzlp NES disrupts its interaction with Msn5p and nuclear export. Although specific phosphorylation sites in Crzlp have not been identified, mutating serines and threonines in the SRR reduces the calcineurin-dependent electrophoretic mobility shift (R. Polizotto, unpubl.), indicating that this region is phosphorylated. Combining these observations we propose that the PIISIQ motif, which is distinct from the NES, mediates a critical association between calcineurin and Crzlp that is required for calcineurin-dependent dephosphorylation of the NES. This dephosphorylation inhibits the interaction between the Crzlp NES and Msn5p, thereby decreasing Crzlp nuclear export. Similarly, Msn5p-mediated export of other cargoes, Pho4p and Miglp, also requires their phosphorylation, and it has been suggested that Msn5p specifically exports phosphoproteins (Kaffman et al. 1998; DeVit and Johnston 1999). However, Farlp binding to Msn5p does not depend on phosphorylation state (Blondel et al. 1999).

\section{Calcineurin-dependent regulation of Crz1p activity}

In unstimulated cells, Crzlp resides in the cytosol because the rate of its nuclear export is greater than the rate of its nuclear import. When calcineurin-dependent signaling is activated, either in response to specific environmental stresses or by addition of $\mathrm{Ca}^{2+}$ to the media, Crzlp rapidly translocates to the nucleus and activates gene expression. Dephosphorylation of Crzlp increases its nuclear import, by causing a conformational change that exposes its nuclear localization signal (NLS) and promotes its interaction with the importin Nmd5p (Polizotto and Cyert 2001). At the same time, dephosphorylation of the Crzlp NES inhibits its interaction with Msn5p, thereby decreasing nuclear export. Thus, dephosphorylation of Crzlp by calcineurin performs two distinct functions: it both increases the rate of Crzlp nuclear import and decreases the rate of its nuclear export. These two effects combine to cause rapid and efficient nuclear accumulation of Crzlp in response to calcineurin activation. Continual dephosphorylation by calcineurin is required to maintain Crzlp nuclear localization. When signaling terminates or calcineurin is inhibited with FK506, Crzlp quickly returns to the cytosol because of its rephosphorylation. The kinases that phosphorylate Crzlp are as yet unidentified, although the rapidity with which Crzlp localization changes suggests that they may reside in the nucleus. Crzlp phosphorylation state oppositely affects its nuclear import and export; thus, the balance between calcineurin and kinase activity tightly regulates Crzlp localization and leads to efficient and reversible transcriptional activation in response to stress.

Although the accessibility of Crzlp to its target genes is clearly regulated through its subcellular localization, nuclear localization alone is apparently not sufficient to fully activate Crzlp. The increase in Crzlp-dependent transcription observed in $m s n 5 \Delta$ cnb1s cells is low despite considerable nuclear accumulation of Crzlp in these cells. Therefore, calcineurin may regulate addi- tional aspects of Crzlp function. Calcineurin activity modulates NFAT binding to DNA (Park et al. 1995; Shaw et al. 1995); however, the ability of Crzlp to bind DNA is not calcineurin-dependent; Crzlp purified from cnb1s cells associates well with the CDRE (Stathopoulos 1998). Alternatively, dephosphorylation of Crzlp by calcineurin may increase its ability to function as a transcriptional activator. Future investigations will address this possibility.

\section{Parallels between calcineurin-regulated pathways in mammals and yeast}

Calcineurin activity induces gene expression in both mammalian cells and yeast by regulating the subcellular localization of a transcription factor; both NFAT and Crzlp show calcineurin-regulated nuclear import and export (Beals et al. 1997; Zhu and McKeon 1999; Okamura et al. 2000; Polizotto and Cyert 2001). Despite their similar regulatory mechanisms, Crzlp and NFAT bind DNA through distinct motifs (Jain et al. 1995; Matheos et al. 1997; Stathopoulos and Cyert 1997) and share little sequence homology. However, two critical domains are conserved in these proteins, the SRR and a calcineurin docking site, both of which are required for calcineurindependent regulation. The SRR, or serine-rich region, contains multiple phosphorylated residues and is required in both proteins for calcineurin-dependent regulation of nuclear transport. Phosphorylation sites in the NFAT SRR contribute to regulation of its nuclear import (Beals et al. 1997; Okamura et al. 2000), whereas phosphorylation of the Crzlp SRR is required for NES activity. Also, both proteins contain a conserved calcineurin docking site. A consensus calcineurin-binding site, PxIxIT, has been defined for NFAT family members (Aramburu et al. 1998). Here we describe a similar motif in Crzlp, PIISIQ, which is required for its interaction with calcineurin in vivo. Crzlp lacking the calcineurin

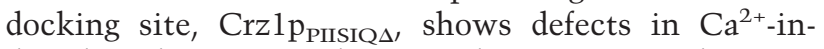
duced nuclear accumulation and transcriptional activation. Therefore, the PIISIQ interaction motif is required for efficient dephosphorylation of Crzlp by calcineurin in vivo. Crzlp $p_{\text {PIISIQ }}$ retains some activity, suggesting that other regions of Crzlp may also promote its interaction with calcineurin. Calcineurin forms stable associations with several other substrates, including the $\mathrm{IP}_{3}$ and ryanodine receptors as well as dynamin 1 (Cameron et al. 1995; Lai et al. 1999|. In each case, when this interaction is perturbed, calcineurin-dependent regulation of the substrate is compromised. Our work shows that in yeast, as in mammalian cells, this interaction occurs at a site on the substrate that is distinct from the phosphorylated region, and is required to target calcineurin to its substrate.

\section{Materials and methods}

Yeast media and general methods

Culture conditions and yeast media were essentially as described (Sherman et al. 1986), except that in synthetic media the 
nutritional supplements were added to twice the indicated levels. When $\mathrm{Ca}^{2+}$ was added to synthetic media, $3.5 \mathrm{~g}$ of ammonium chloride was substituted for ammonium sulfate. Buffered YPD media was made with $40 \mathrm{mM}$ succinate, and the $\mathrm{pH}$ was adjusted to 5.5 with $\mathrm{KOH}$.

All recombinant DNA procedures were carried out according to standard protocols (Ausubel et al. 1987). Yeast cells were transformed using the lithium acetate method, and bacterial cells were transformed by electroporation (Ausubel et al. 1987). DNA templates for sequencing were prepared according to the manufacturer's instructions (Wizard Miniprep kit, Promega). Sequencing was also carried out according to the manufacturer's instructions (Sequenase, USB) using $\left[\alpha-{ }^{35} S\right]$ dATP (Amersham).

\section{Yeast strains}

The yeast strains used in this study are described in Table 1. ASY788 was created by homologous recombination using an msn5::loxP-kanMX-loxP disruption cassette generated by PCR (Guldener et al. 1996). LBY172 was made by crossing ASY788 to MCY3-1D. The resulting diploid was sporulated and the double mutant selected. pAMS367 containing the CDRE::1acZ reporter was integrated at the URA3 locus of LBY196, ASY456, and ASY569.

\section{Plasmids}

The plasmids used in this study are described in Table 2. pLMB134 was created by first annealing complementary oligonucleotides encoding the SV40 large T antigen NLS (Kalderon et al. 1984a,b) flanked by SpeI and HindIII restriction sites. The annealed oligonucleotides were then ligated into pOM4, a $3 x$ GFP vector (Polizotto and Cyert 2001), digested with SpeI and HindIII. A series of in-frame 3xGFP-SV40NLS-Crzlp fusions were constructed in the following manner: PCR was used to amplify the indicated regions of CRZ1 and to introduce HindIII and SalI restriction sites flanking the PCR product. The PCR product was first ligated into a bacterial vector, PCR2.1TOPO, using the TOPO-TA kit (Invitrogen), and then shuttled into pLMB134 predigested with HindIII and SalI. pLMB184 and pLMB186 were constructed as above except HindIII and ClaI restriction sites were used. pLMB189, pLMB193, pLMB218,
pLMB224, and pLMB 226 were constructed using PCR to amplify the specified regions of CRZ1 with NcoI and BamHI sites flanking the PCR product. PCR products were then ligated into pACTII to create an in-frame fusion with the Gal4p activation domain. pLMB230 was constructed by a three-way ligation of base pairs 1-930 of CRZ1 flanked by HindIII and ClaI sites and base pairs 1021-2037 of CRZ1 flanked by ClaI and SalI sites into pOM4 digested with HindIII and SalI. pLMB231 was constructed similarly but using base pairs 1-990 and 1009-2037 of CRZ1.

\section{$\beta$-Galactosidase assays}

Quantitative assay Exponentially growing yeast cells in selective synthetic media were diluted to an $\mathrm{OD}_{600}$ of 0.2 in buffered YPD and grown at $30^{\circ} \mathrm{C}$ for $7 \mathrm{~h}$. Cells were harvested and washed once, and the cell pellets were frozen. Cells were broken using glass bead lysis (Withee et al. 1997) in Breaking Buffer (100 $\mathrm{mM}$ Tris at $\mathrm{pH} 8,20 \%$ glycerol, $1 \mathrm{mM}$ DTT) plus protease inhibitors (1 mM PMSF, $1 \mathrm{mM}$ benzamidine, $2 \mu \mathrm{g} / \mathrm{mL}$ leupeptin, $2 \mu \mathrm{g} / \mathrm{mL}$ aprotinin). Protein concentrations of the resulting cell extracts were determined using the Bio-Rad protein assay. $\beta$-Galactosidase activity was measured at $30^{\circ} \mathrm{C}$ in a microtiter plate using $75 \mu \mathrm{g}$ of total protein, $100 \mu \mathrm{L}$ of Z-buffer $(100 \mathrm{mM}$ $\mathrm{Na}_{2} \mathrm{HPO}_{4}, 40 \mathrm{mM} \mathrm{NaH} \mathrm{PO}_{4}, 10 \mathrm{mM} \mathrm{KCl}, 1 \mathrm{mM} \mathrm{MgSO}$, $0.027 \% \beta$-mercaptoethanol), and $40 \mu \mathrm{L}$ of $4 \mathrm{mg} / \mathrm{mL}$ ONPG (Onitrophenyl- $\beta$-D-galactopyranoside, Sigma). Values result from the average of two independent extracts each measured in triplicate. Alternatively, cells were grown for $5 \mathrm{~h}$ in buffered YPD with or without $100 \mathrm{mM} \mathrm{CaCl}_{2}$ and measured at room temperature in a microtiter plate using $90 \mu \mathrm{L}$ of $\mathrm{Z}$ buffer and $20 \mu \mathrm{L}$ of ONPG.

Qualitative assay Yeast colonies were scored for $\beta$-galactosidase activity as described (Stathopoulos and Cyert 1997). Blue colonies were selected after overnight incubation with $0.2 \mathrm{mg} /$ mL X-gal (Sigma).

\section{Genetic screening}

Calcineurin mutant strains containing the CDRE::1acZ reporter gene (ASY456 or ASY569) were grown to log phase

Table 1. Yeast strains used in this study

\begin{tabular}{|c|c|c|}
\hline Strain & Relevant genotype & Source \\
\hline YPH499 & 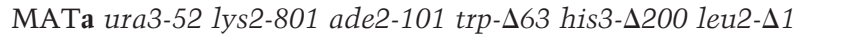 & Sikorski and Hieter 1989 \\
\hline YPH500 & 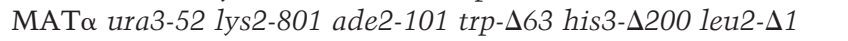 & Sikorski and Hieter 1989 \\
\hline DD12 & Same as YPH499 except cnb1::URA::hisG & Cyert and Thorner 1992 \\
\hline MCY3-ID & Same as YPH500 except cnb1::LEU2 & Cyert and Thorner 1992 \\
\hline PJ69-4A & $\begin{array}{l}\text { MATa trp1-901 leu2-3,112 ura3-52 his3-200 gal4s gal80s } \\
\text { GAL2-ADE2 LYS2::GAL1-HIS3 met2::GAL7-lacZ }\end{array}$ & James et al. 1996 \\
\hline ASY3 & Same as PJ69-4A except cnb1::URA3::hisg & A. Stathopoulos-Gerontides \\
\hline ASY456 & Same as YPH499 except ura3-52::URA3-4xCDRE & A. Stathopoulos-Gerontides \\
\hline ASY472 & Same as YPH499 except crzl::1oxP-kanMX-loxP & Stathopoulos and Cyert 1997 \\
\hline ASY475 & Same as DD12 except crzl::1oxP-kanMX-loxP & Stathopoulos and Cyert 1997 \\
\hline ASY569 & Same as MCY3-1D except ura3-52::URA3-4xCDRE & A. Stathopoulos-Gerontides \\
\hline ASY788 & Same as YPH499 except msn5::1oxP-kanMX-loxP & A. Stathopoulos-Gerontides \\
\hline ASY834 & Same as ASY472 except ura3-52::TRP1-4xCDRE & A. Stathopoulos-Gerontides \\
\hline ASY835 & Same as ASY475 except ura3-52::TRP1-4xCDRE & A. Stathopoulos-Gerontides \\
\hline LBY172 & Same as ASY788 except cnb1::LEU2 & This study \\
\hline LBY196 & Same as LBY172 except ura3-52::URA3-4xCDRE & This study \\
\hline HFY133 & ura3-1 ade2-1 trp1-1 his3-11,15 leu2-3,11 can1-100 nmd5::HIS3 & A. Jacobson \\
\hline
\end{tabular}


Table 2. Plasmids used in this study

\begin{tabular}{|c|c|c|}
\hline Plasmid & Description & Reference \\
\hline AMS367 & URA3-4xCDRE integrating plasmid & Stathopoulos and Cyert 1997 \\
\hline AMS446 & HA-CRZ1 & Stathopoulos and Cyert 1997 \\
\hline AMS463 & GFP-CRZ1 & Stathopoulos-Gerontides et al. 1999 \\
\hline pVT CNA2 & CNA2 trunc & Withee et al. 1997 \\
\hline pOM4 & $3 x G F P$ vector & Polizotto and Cyert 2001 \\
\hline LMB127 & 3xGFP-CRZ1 & This study \\
\hline LMB134 & 3xGFP-SV40NLS vector & This study \\
\hline LMB148 & CRZ1 in LMB134 & This study \\
\hline LMB158 & CRZ1 (aa 186-422) in LMB134 & This study \\
\hline LMB160 & CRZ1 (aa 186-340) in LMB134 & This study \\
\hline LMB162 & CRZ1 (aa 186-279) in LMB134 & This study \\
\hline LMB163 & CRZ1 (aa 186-237) in LMB134 & This study \\
\hline LMB165 & CRZ1 (aa 433-679) in LMB134 & This study \\
\hline LMB178 & CRZ1 (aa 1-186) in LMB134 & This study \\
\hline LMB180 & CRZ1 (aa 186-310) in LMB134 & This study \\
\hline LMB184 & CRZ1 (aa $\Delta 186-233$ ) in LMB 134 & This study \\
\hline LMB186 & CRZ1 (mSRR) in LMB 134 & This study \\
\hline LMB199 & CRZ1 (aa 201-279) in LMB134 & This study \\
\hline LMB207 & CRZ1 (aa 186-250) in LMB134 & This study \\
\hline LMB211 & mSRR (aa 186-279) in LMB134 & This study \\
\hline LMB228 & PIISIQ $\Delta$ (aa 186-340) in LMB134 & This study \\
\hline LMB189 & GAL4AD-CRZ1 (aa 186-340) & This study \\
\hline LMB193 & GAL4AD-CRZ1 (aa 186-279) & This study \\
\hline LMB218 & GAL4AD-mSRR (aa 186-279) & This study \\
\hline LMB224 & GAL4AD-PIISIQ $\Delta$ (aa 186-340) & This study \\
\hline LMB226 & GAL4AD-CRZ1 (aa 186-310) & This study \\
\hline LMB230 & CRZ1 (aa $\Delta 311-340$ ) in pOM4 & This study \\
\hline LMB231 & CRZ1 (aa $\Delta 331-336)$ in pOM4 & This study \\
\hline ВM3694 & GAL4BD-MSN5 & DeVit and Johnston 1999 \\
\hline BJP2014 & GAL4BD-CNA1 & Jiang and Cyert 1999 \\
\hline
\end{tabular}

$\left(\mathrm{OD}_{600}=0.8-1.0\right)$ and plated onto selective agar plates. Cells were subjected to UV mutagenesis to $\sim 50 \%$ killing in a UV Stratalinker (Stratagene). $\beta$-Galactosidase filter lifts were performed and blue colonies were selected as described (Stathopoulos and Cyert 1997). There were 40 mutants identified from 128,000 colonies screened. The mutants were tested for dominance or recessiveness by mating to a $c n b 1 \Delta$ strain and checking CDRE::1acZ reporter activation in the diploid. MATa and MAT $\alpha$ mutants were crossed to each other to place them into complementation groups. The majority of mutants did not fall into groups, but one complementation group of five members was defined. Mutants were then tested for specificity by selecting those that failed to activate a mutant version of the CDRE reporter. In addition, a requirement for CRZ1 was established by deleting $C R Z 1$ in the mutant strains and assaying CDRE::lacZ reporter activation. Mutants were cloned by complementation using the YPH1 genomic library (ATCC \#77162); complementing plasmids were rescued, and the ends of the insert were sequenced. The resulting sequence was compared to the genome using BLAST to determine the ORFs contained on the plasmids. The sequence shared by both complementing plasmids contained 4 ORFs on Chromosome IV: YDR334w, MSN5, YDR336w, and MRPS28. Allelic analysis with an $m s n 5 \Delta$ strain confirmed the mutation was in MSN5.

\section{Immunoblot analysis}

Yeast cultures were grown to $\log$ phase at $21^{\circ} \mathrm{C}$, harvested, and the cell pellets were frozen. FK520 (Merck), in 90\% ethanol,
$10 \%$ Tween-20, was added to $2 \mu \mathrm{g} / \mathrm{mL}$ where indicated. Protein extracts were made in Buffer 88 (20 mM HEPES at pH 6.8, 150 $\mathrm{mM}$ KOAc, $250 \mathrm{mM}$ Sorbitol, $2 \mathrm{mM} \mathrm{MgOAc}, 2 \mathrm{mM}$ DTT, protease inhibitors) using glass bead lysis as described above. Samples $(10 \mu \mathrm{g}$ of total protein in wild-type and cnb1s strains, or $50 \mu \mathrm{g}$ of total protein in $m s n 5 \Delta$ strains) were resolved on a $7 \%$ reducing gel. Where indicated, extracts were treated with 200 units of $\lambda$ phosphatase (NEB) at $30^{\circ}$ for 30 min. HA-Crzlp was detected using monoclonal anti-HA 12CA5 antiserum (Roche Molecular Biochemicals) and anti-mouse IgG-coupled HRP secondary antibody (Amersham). GFP-Crzlp was detected using a monoclonal GFP antibody (Covance) and anti-mouse IgG coupled HRP secondary antibody (Amersham). Immunoblots were developed using ECL (Amersham).

\section{Fluorescence microscopy}

Living cells expressing green fluorescent protein (GFP) were visualized as described (Stathopoulos-Gerontides et al. 1999) but using an Eclipse E600 microscope (Nikon) with fluorescence optics and an HB100 mercury lamp. Fluorescein filter sets (Chroma) were used to visualize GFP, and digital images were captured with a CCD 4742-95 camera (Hammamatsu) and QED software (QED Imaging). Cells were treated with $10 \mu \mathrm{g} / \mathrm{mL}$ cycloheximide for $20 \mathrm{~min}$ to inhibit protein synthesis where noted. Also, $\mathrm{CaCl}_{2}$ was added to $200 \mathrm{mM}$, and FK506 (Fugisawa) in $90 \%$ ethanol, $10 \%$ Tween- 20 was added to $5 \mu \mathrm{g} / \mathrm{mL}$ as indicated. 


\section{Two-hybrid analysis}

For the Crz1p/Msn5p interaction, strains containing the twohybrid constructs to be tested were spotted onto selective agar media using fivefold serial dilutions beginning at an $\mathrm{OD}_{600}$ of 0.05. Plates were incubated at $21^{\circ} \mathrm{C}$ for $5 \mathrm{~d}$. The interaction was scored by assessing growth on media lacking histidine. For the Crzlp/calcineurin interaction, yeast were spotted onto selective agar media containing $100 \mathrm{mM} \mathrm{CaCl}_{2}$. Fivefold serial dilutions beginning at an $\mathrm{OD}_{600}$ of 1.0 were used, and plates were incubated at $30^{\circ} \mathrm{C}$ for $2-3 \mathrm{~d}$.

\section{Acknowledgments}

We thank Renee Polizotto for providing reagents and for helpful discussions about Crzlp nuclear transport, and Rachel Smith and Victoria Heath for critical reading of the manuscript. We are grateful to the following people for providing strains and plasmids: Mark Johnston (GAL4BD-MSN5), Allan Jacobson (nmd5s), Bo Jiang (GBT9-CNA1), Phil James (PJ69-4A), and Angela Stathopolous-Gerontides for numerous strains and constructs. M.S.C. is supported by National Institutes of Health (NIH) research grant GM-48729. L.M.B. is supported by NIH training grant 5T32GM07276.

The publication costs of this article were defrayed in part by payment of page charges. This article must therefore be hereby marked "advertisement" in accordance with 18 USC section 1734 solely to indicate this fact.

\section{References}

Alepuz, P.M., Matheos, D., Cunningham, K.W., and Estruch, F. 1999. The Saccharomyces cerevisiae RanGTP-binding protein msn5p is involved in different signal transduction pathways. Genetics 153: 1219-1231.

Aramburu, J., Garcia-Cozar, F., Raghavan, A., Okamura, H., Rao, A., and Hogan, P.G. 1998. Selective inhibition of NFAT activation by a peptide spanning the calcineurin targeting site of NFAT. Mol. Cell 1: 627-637.

Ausubel, F.M., Brent, R., Kingston, R.E., Moore, D.D., Seidman, J.G., Smith, J.A., and Struhl, K. 1987. Current protocols in molecular biology. John Wiley, New York, NY.

Beals, C.R., Clipstone, N.A., Ho, S.N., and Crabtree, G.R. 1997. Nuclear localization of NF-ATc by a calcineurin-dependent, cyclosporin-sensitive intramolecular interaction. Genes \& Dev. 11: 824-834.

Blondel, M., Alepuz, P.M., Huang, L.S., Shaham, S., Ammerer, G., and Peter, M. 1999. Nuclear export of Farlp in response to pheromones requires the export receptor Msn5p/Ste21p. Genes \& Dev. 13: 2284-2300.

Cameron, A.M., Steiner, J.P., Roskams, A.J., Ali, S.M., Ronnett, G.V., and Snyder, S.H. 1995. Calcineurin associated with the inositol 1,4,5-trisphosphate receptor-FKBP12 complex modulates $\mathrm{Ca}^{2+}$ flux. Cell 83: 463-472.

Chin, E.R., Olson, E.N., Richardson, J.A., Yang, Q., Humphries, C., Shelton, J.M., Wu, H., Zhu, W., Bassel-Duby, R., and Williams, R.S. 1998. A calcineurin-dependent transcriptional pathway controls skeletal muscle fiber type. Genes \& Dev. 12: 2499-2509.

Clipstone, N.A. and Crabtree, G.R. 1992. Identification of calcineurin as a key signalling enzyme in T-lymphocyte activation. Nature 357: 695-697.

Cunningham, K.W. and Fink, G.R. 1994. Calcineurin-dependent growth control in Saccharomyces cerevisiae mutants lacking PMC1, a homolog of plasma membrane $\mathrm{Ca}^{2+}$
ATPases. J. Cell Biol. 124: 351-363.

. 1996. Calcineurin inhibits VCX1-dependent $\mathrm{H}^{+} / \mathrm{Ca}^{2+}$ exchange and induces $\mathrm{Ca}^{2+}$ ATPases in Saccharomyces cerevisiae. Mol. Cell. Biol. 16: 2226-2237.

Cyert, M.S. and Thorner, J. 1992. Regulatory subunit (CNB1 gene product) of yeast $\mathrm{Ca}^{2+} /$ calmodulin-dependent phosphoprotein phosphatases is required for adaptation to pheromone. Mol. Cell. Biol. 12: 3460-3469.

Cyert, M.S., Kunisawa, R., Kaim, D., and Thorner, J. 1991. Yeast has homologs (CNA1 and CNA2 gene products) of mammalian calcineurin, a calmodulin-regulated phosphoprotein phosphatase. Proc. Nat1. Acad. Sci. 88: 7376-7380.

de la Pompa, J.L., Timmerman, L.A., Takimoto, H., Yoshida, H., Elia, A.J., Samper, E., Potter, J., Wakeham, A., Marengere, L., Langille, B.L., et al. 1998. Role of the NF-ATc transcription factor in morphogenesis of cardiac valves and septum. $\mathrm{Na}$ ture 392: 182-186.

DeVit, M.J. and Johnston, M. 1999. The nuclear exportin Msn5 is required for nuclear export of the Mig1 glucose repressor of Saccharomyces cerevisiae. Curr. Biol. 9: 1231-1241.

Farcasanu, I.C., Hirata, D., Tsuchiya, E., Nishiyama, F., and Miyakawa, T. 1995. Protein phosphatase 2B of Saccharomyces cerevisiae is required for tolerance to manganese, in blocking the entry of ions into the cells. Eur. J. Biochem. 232: 712-717.

Fischer, U., Huber, J., Boelens, W.C., Mattaj, I.W., and Luhrmann, R. 1995. The HIV-1 Rev activation domain is a nuclear export signal that accesses an export pathway used by specific cellular RNAs. Cell 82: 475-483.

Flanagan, W.M., Corthesy, B., Bram, R.J., and Crabtree, G.R. 1991. Nuclear association of a T-cell transcription factor blocked by FK-506 and cyclosporin A. Nature 352: 803-807.

Fornerod, M., Ohno, M., Yoshida, M., and Mattaj, I.W. 1997. CRM1 is an export receptor for leucine-rich nuclear export signals. Cell 90: 1051-1060.

Graef, I.A., Chen, F., Chen, L., Kuo, A., and Crabtree, G.R. 2001. Signals transduced by $\mathrm{Ca}^{2+} /$ calcineurin and NFATc3/c4 pattern the developing vasculature. Cell 105: 863-875.

Guldener, U., Heck, S., Fielder, T., Beinhauer, J., and Hegemann, J.H. 1996. A new efficient gene disruption cassette for repeated use in budding yeast. Nucleic Acids Res. 24: 25192524.

Haro, R., Garciadeblas, B., and Rodriguez-Navarro, A. 1991. A novel P-type ATPase from yeast involved in sodium transport. FEBS Lett. 291: 189-191.

Jain, J., McCaffrey, P.G., Miner, Z., Kerppola, T.K., Lambert, J.N., Verdine, G.L., Curran, T., and Rao, A. 1993. The T-cell transcription factor NFATp is a substrate for calcineurin and interacts with Fos and Jun. Nature 365: 352-355.

Jain, J., Burgeon, E., Badalian, T.M., Hogan, P.G., and Rao, A. 1995. A similar DNA-binding motif in NFAT family proteins and the Rel homology region. J. Biol. Chem. 270: 41384145 .

James, P., Halladay, J., and Craig, E.A. 1996. Genomic libraries and a host strain designed for highly efficient two-hybrid selection in yeast. Genetics 144: 1425-1436.

Jiang, B. and Cyert, M.S. 1999. Identification of a novel region critical for calcineurin function in vivo and in vitro. J. Biol. Chem. 274: 18543-18551.

Kaffman, A., Rank, N.M., O'Neill, E.M., Huang, L.S., and O'Shea, E.K. 1998. The receptor Msn5 exports the phosphorylated transcription factor Pho4 out of the nucleus. $\mathrm{Na}$ ture 396: 482-486.

Kalderon, D., Richardson, W.D., Markham, A.F., and Smith, A.E. 1984a. Sequence requirements for nuclear location of simian virus 40 large-T antigen. Nature 311: 33-38. 
Kalderon, D., Roberts, B.L., Richardson, W.D., and Smith, A.E. 1984b. A short amino acid sequence able to specify nuclear location. Cell 39: 499-509.

Kuno, T., Tanaka, H., Mukai, H., Chang, C.D., Hiraga, K., Miyakawa, T., and Tanaka, C. 1991. cDNA cloning of a calcineurin B homolog in Saccharomyces cerevisiae. Biochem. Biophys. Res. Commun. 180: 1159-1163.

Kunzler, M., Trueheart, J., Sette, C., Hurt, E., and Thorner, J. 2001. Mutations in the YRB1 gene encoding yeast ran-binding-protein-1 that impair nucleocytoplasmic transport and suppress yeast mating defects. Genetics 157: 1089-1105.

Lai, M.M., Hong, J.J., Ruggiero, A.M., Burnett, P.E., Slepnev, V.I., De Camilli, P., and Snyder, S.H. 1999. The calcineurindynamin 1 complex as a calcium sensor for synaptic vesicle endocytosis. J. Biol. Chem. 274: 25963-25966.

Liu, J., Farmer, J.D., Jr., Lane, W.S., Friedman, J., Weissman, I., and Schreiber, S.L. 1991a. Calcineurin is a common target of cyclophilin-cyclosporin A and FKBP-FK506 complexes. Cell 66: 807-815.

Liu, Y., Ishii, S., Tokai, M., Tsutsumi, H., Ohki, O., Akada, R., Tanaka, K., Tsuchiya, E., Fukui, S., and Miyakawa, T. 1991b. The Saccharomyces cerevisiae genes (CMP1 and CMP2) encoding calmodulin-binding proteins homologous to the catalytic subunit of mammalian protein phosphatase 2B. Mol. Gen. Genet. 227: 52-59.

Mahanty, S.K., Wang, Y., Farley, F.W., and Elion, E.A. 1999. Nuclear shuttling of yeast scaffold Ste5 is required for its recruitment to the plasma membrane and activation of the mating MAPK cascade. Cell 98: 501-512.

Matheos, D.P., Kingsbury, T.J., Ahsan, U.S., and Cunningham, K.W. 1997. Tcnlp/Crzlp, a calcineurin-dependent transcription factor that differentially regulates gene expression in Saccharomyces cerevisiae. Genes \& Dev. 11: 3445-3458.

Mazur, P., Morin, N., Baginsky, W., el-Sherbeini, M., Clemas, J.A., Nielsen, J.B., and Foor, F. 1995. Differential expression and function of two homologous subunits of yeast 1,3- $\beta$-Dglucan synthase. Mol. Cell. Biol. 15: 5671-5681.

Mendoza, I., Rubio, F., Rodriguez-Navarro, A., and Pardo, J.M. 1994. The protein phosphatase calcineurin is essential for $\mathrm{NaCl}$ tolerance of Saccharomyces cerevisiae. J. Biol. Chem. 269: 8792-8796.

Molkentin, J.D., Lu, J.R., Antos, C.L., Markham, B., Richardson, J., Robbins, J., Grant, S.R., and Olson, E.N. 1998. A calcineurin-dependent transcriptional pathway for cardiac hypertrophy. Cell 93: 215-228.

Moser, M.J., Geiser, J.R., and Davis, T.N. 1996. $\mathrm{Ca}^{2+}$-calmodulin promotes survival of pheromone-induced growth arrest by activation of calcineurin and $\mathrm{Ca}^{2+}$-calmodulin-dependent protein kinase. Mol. Cell. Biol. 16: 4824-4831.

Nakamura, T., Liu, Y., Hirata, D., Namba, H., Harada, S., Hirokawa, T., and Miyakawa, T. 1993. Protein phosphatase type 2B (calcineurin)-mediated, FK506-sensitive regulation of intracellular ions in yeast is an important determinant for adaptation to high salt stress conditions. EMBO J. 12: 4063 4071.

Okamura, H., Aramburu, J., Garcia-Rodriguez, C., Viola, J.P., Raghavan, A., Tahiliani, M., Zhang, X., Qin, J., Hogan, P.G., and Rao, A. 2000. Concerted dephosphorylation of the transcription factor NFAT1 induces a conformational switch that regulates transcriptional activity. Mol. Cell 6: 539-550.

O'Keefe, S.J., Tamura, J., Kincaid, R.L., Tocci, M.J., and O'Neill, E.A. 1992. FK-506- and CsA-sensitive activation of the in terleukin-2 promoter by calcineurin. Nature 357: 692-694.

Ossareh-Nazari, B., Bachelerie, F., and Dargemont, C. 1997. Evidence for a role of CRM1 in signal-mediated nuclear protein export. Science 278: 141-144.
Park, J., Yaseen, N.R., Hogan, P.G., Rao, A., and Sharma, S 1995. Phosphorylation of the transcription factor NFATp inhibits its DNA binding activity in cyclosporin A-treated human B and T cells. J. Biol. Chem. 270: 20653-20659.

Polizotto, R.S. and Cyert, M.S. 2001. Calcineurin-dependent nuclear import of the transcription factor Crzlp requires Nmd5p. J. Cell Biol. 154: 951-960.

Pozos, T.C., Sekler, I., and Cyert, M.S. 1996. The product of HUM1, a novel yeast gene, is required for vacuolar $\mathrm{Ca}^{2+} / \mathrm{H}^{+}$ exchange and is related to mammalian $\mathrm{Na}^{+} / \mathrm{Ca}^{2+}$ exchangers. Mol. Cell. Biol. 16: 3730-3741.

Ranger, A.M., Grusby, M.J., Hodge, M.R., Gravallese, E.M., de la Brousse, F.C., Hoey, T., Mickanin, C., Baldwin, H.S., and Glimcher, L.H. 1998. The transcription factor NF-ATc is essential for cardiac valve formation. Nature 392: 186-190.

Rudolph, H.K., Antebi, A., Fink, G.R., Buckley, C.M., Dorman, T.E., LeVitre, J., Davidow, L.S., Mao, J.I., and Moir, D.T. 1989. The yeast secretory pathway is perturbed by mutations in PMR1, a member of a $\mathrm{Ca}^{2+}$ ATPase family. Cell 58: $133-145$.

Shaw, K.T., Ho, A.M., Raghavan, A., Kim, J., Jain, J., Park, J., Sharma, S., Rao, A., and Hogan, P.G. 1995. Immunosuppressive drugs prevent a rapid dephosphorylation of transcription factor NFAT1 in stimulated immune cells. Proc. Natl. Acad. Sci. 92: 11205-11209.

Sherman, F., Fink, G.R., and Hicks, J.B. 1986. Methods in yeast genetics. Cold Spring Harbor Laboratory, Cold Spring Harbor, NY.

Sikorski, R.S. and Hieter, P. 1989. A system of shuttle vectors and yeast host strains designed for efficient manipulation of DNA in Saccharomyces cerevisiae. Genetics 122: 19-27.

Stade, K., Ford, C.S., Guthrie, C., and Weis, K. 1997. Exportin 1 (Crmlp) is an essential nuclear export factor. Cell 90: 10411050.

Stathopoulos, A.M. 1998. "Calcineurin regulates the CRZ1 transcription factor to control gene expression in Saccharomyces cerevisiae." Ph.D. thesis, Stanford University, Stanford, CA.

Stathopoulos, A.M. and Cyert, M.S. 1997. Calcineurin acts through the CRZ1/TCN1-encoded transcription factor to regulate gene expression in yeast. Genes \& Dev. 11: 34323444.

Stathopoulos-Gerontides, A., Guo, J.J., and Cyert, M.S. 1999. Yeast calcineurin regulates nuclear localization of the Crzlp transcription factor through dephosphorylation. Genes \& Dev. 13: 798-803.

Wen, W., Meinkoth, J.L., Tsien, R.Y., and Taylor, S.S. 1995. Identification of a signal for rapid export of proteins from the nucleus. Cell 82: 463-473.

Withee, J.L., Mulholland, J., Jeng, R., and Cyert, M.S. 1997. An essential role of the yeast pheromone-induced $\mathrm{Ca}^{2+}$ signal is to activate calcineurin. Mol. Biol. Cell 8: 263-277.

Yoshida, K. and Blobel, G. 2001. The karyopherin kap142p/ msn5p mediates nuclear import and nuclear export of different cargo proteins. J. Cell Biol. 152: 729-740.

Zhu, J. and McKeon, F. 1999. NF-AT activation requires suppression of Crm1-dependent export by calcineurin. Nature 398: $256-260$. 


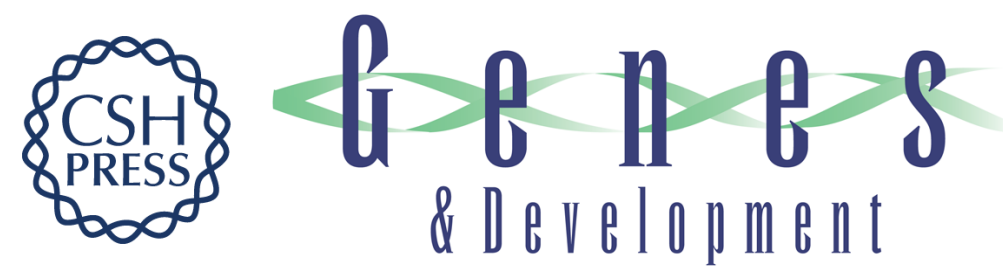

\section{Calcineurin-dependent regulation of Crz1p nuclear export requires Msn5p and a conserved calcineurin docking site}

Leila M. Boustany and Martha S. Cyert

Genes Dev. 2002, 16:

Access the most recent version at doi:10.1101/gad.967602

References This article cites 56 articles, 27 of which can be accessed free at: http://genesdev.cshlp.org/content/16/5/608.full.htmI\#ref-list-1

License

Email Alerting

Receive free email alerts when new articles cite this article - sign up in the box at the top Service right corner of the article or click here.

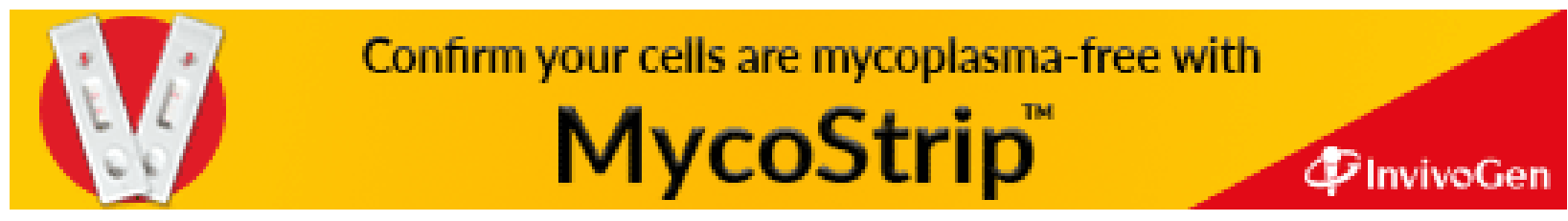

